\title{
Triangulating Findings from an Instruction-Based Community Engagement Project
}

This paper reports on the assessment of initial data from an ongoing, award-winning service learning project called "Computer Training for Persons with Intellectual Disabilities." The project was researched, designed, and implemented by Masters in Library Science (MLIS) students at a large southeastern university. The two explicit goals of the project were to assess the effectiveness of the core curriculum in preparing students to undertake such a project and to provide technology literacy to clients with intellectual disabilities. However, the three implicit goals were to benefit the students, the clients, and the community partner through the process of engagement. The data reported are based on the first eighteen months of the project and are gathered from an exercise mapping the students' perceptions of the usefulness of the core curriculum, their written reflections concerning their participation in the project, and their records concerning client progress through the instruction. The student data are corroborated through an interview session with the community partner. The methods and results reflect a qualitative text analysis protocol since the first phase of the project was exploratory and the population was limited. Quantitative data reflect only simple descriptive statistics due to sample size and lack of comparative data. Results indicate that the goals of the original project are being met, and other corollary effects, such as students' attitudes concerning underrepresented populations were affected positively and constructively. We also identify necessary revisions and challenges as the project progresses, and numerous avenues for further research.

n another 2011 article, we described a project design and conceptual framework for a service learning component of the MLIS program at a major southeastern university. ${ }^{1}$ This project, which brings technology instruction to clients with intellectual disabilities, is intended to supply an applied model for instruction-based service learning, something which has been lacking in the literature and in the pedagogy, forcing instructors to "reinvent the wheel" for each instruction based service learning course opportunity or project. While many course specific models exist, providing individualized approaches to incorporating service learning, there was no model which linked service learning programmatically to a core of courses which could be used to guide generalized development and improvement of service learning initiatives. The benefits of such participation for LIS students are well documented and can lead to increased involvement with community partners when students enter the

\section{Maryann S. Whitaker and Dan Albertson}

Maryann S. Whitaker is a doctoral student and Dan Albertson is an Assistant Professor in the School of Library and Information Studies at the University of Alabama in Tuscaloosa. Submitted for review November 24, 2010; accepted for publication February 11, 2011.

Reference \& User Services Quarterly, vol. 51, no. 1, pp. 49-59

(c) 2011 American Library Association. All rights reserved.

Permission granted to reproduce for nonprofit, educational use. 


\section{FEATURE}

profession. ${ }^{2}$ Indeed, LIS education provides a natural fit for such service learning endeavors.

The purpose of this article is to report an initial assessment of the service learning project, after the first 18 months following its inception. This assessment will assist in determining needed revisions and additional mechanisms for expansion of the project, as well as providing future avenues for research. Ostensibly, the community service partnership fulfilled the twofold purposes of enabling hands-on application of principles learned from the Masters in Library Science (MLIS) core curriculum (planning, design, management, technology, and instructional skills) and providing basic computer literacy skills to intellectually disabled clients through a partnership with a nonprofit community service organization. In addition, the community partner benefited from association with the university. The ultimate goal of the project is to provide students with a context for lifelong community partnership endeavors as change agents to the communities in which they serve as library professionals. The context for our evaluation, through collaborative endeavors with other LIS programs, will be based on an ongoing and award-winning service-learning project titled, "Computer Training for Persons with Intellectual Disabilities" (CTPD).

\section{LITERATURE REVIEW}

In the summer of 2000, the American Library Association (ALA) released the Information Literacy Community Partnerships Initiative, a proposal that encouraged libraries and library professionals to build information literacy partnerships among their peers as well as with other organizations and institutions in their communities. Since the release of ALA's initiative, there has been a marked increase in the number of service learning opportunities offered within LIS programs, many of which have been instruction-based projects with a focus on the promotion of information literacy. ${ }^{3}$ The central goal of the partnerships is to empower underserved or underrepresented populations with the information literacy skills necessary to access the resources and services of an increasingly digitized world. This initiative also strongly advances the need for library and information studies (LIS) educational programs to offer service learning options as part of the curriculum in which MLIS students can collaborate with community partners to promote information literacy in the communities they serve. ${ }^{4}$ By participating in service learning projects, MLIS students are able to enhance their education through experiential learning and acquire some familiarity with the professional responsibilities of a librarian within a community. ${ }^{5}$

Central to the concerns of service learning, especially in a technology framework, is critical literacy theory, which addresses the (dis)empowerment of underrepresented groups and the hegemonic tendencies of the dominant culture to marginalize them. ${ }^{6}$ Libraries are especially well situated to address this issue since they serve as the interdisciplinary nucleus of information access for all university departments. ${ }^{7}$
Library schools provide trained professionals who will occupy positions as professional librarians in colleges and universities, as well as in $\mathrm{K}-12$ schools and public libraries. These professionals will be required to serve populations that represent not only the mainstream, but those that are culturally diverse, elderly, and physically and/or intellectually challenged. ${ }^{8}$

In the arena of service learning, multiple theoretical stances impact pedagogical and experiential concerns, creating a rich environment for students to engage in deeper conceptual thinking about the nature of reality, knowing, and doing. These include critical literacy, co-cultural, and social capital theories. ${ }^{9}$ One of the goals of the CTPD project is to encourage students to assume the role of change agents as professional literacy advocates for culturally marginalized groups. ${ }^{10}$ Student reflections add value by furnishing information that allows program administrators and faculty to adjust course content to accommodate service learning needs. ${ }^{11}$ However, these personal reflections of their roles and responsibilities also provide an important source of data to determine (1) the efficacy of the program as it relates to competencies that enable future librarians to participate in the technology literacy needs of a community client base, (2) the effectiveness of the instruction provided to the clients, and (3) the effect upon attitudes and perceptions of participating students such that they adopt a service-oriented worldview. Rockquemore and Schaffer describe much the same outcomes for their threestage model—shock, normalization, and engagement—of cognitive development of students as they progress through certain service-learning projects. ${ }^{12}$ Citing Eyler and Giles, they remind us that active engagement in undertakings that empower a community is one of the central goals of servicelearning in the service of social change. So, any such projects dealing specifically with forms of literacy are intrinsically political and related to issues of power and capital, or the lack thereof. ${ }^{13}$

\section{PROJECT OVERVIEW}

The project being evaluated is the first phase, covering eighteen months, of an ongoing, award-winning service learning project called "Computer Training for Persons with Intellectual Disabilities." This instruction-based project was initiated and is overseen by a faculty member in the School of Library and Information Studies (SLIS) at a large southeastern university. It has been undertaken in collaboration with a community partner, a local nonprofit organization, an adult habilitation center which offers a variety of programs including, but not limited to, adult companionship, residential habilitation, respite care, and sponsored employment. The project received an award for Excellence in Community Engagement and Outstanding Faculty-Initiated Engagement Effort. This type of service learning project can be especially applicable for generalizing student experiences that connect hands-on activities with the foundations of LIS. 


\section{Student Involvement}

The project was designed to promote technology literacy for underrepresented populations by teaching basic technology competencies to several clients with intellectual disabilities at the community partner's facility. MLIS students were tasked with researching, designing, and implementing the instruction modules used to instruct the clients. Students participating in the project were required to have completed at least 12 hours in the MLIS program, but may or may not have taken the same courses at the point of their participation in the program. Students were recruited from both on site and distance education MLIS programs, and were given the choice to participate as enrollees in a 1-6 hour Directed Research course or on a voluntary basis. Distance education students, some international from as far away as India, also participated in the research component of the project. Students were tasked with all phases of the program, which included executing research (grant writing, presenting posters, and writing papers), setting up and helping with technology, creating and refining instructional modules and tracks, providing instruction, collecting data, recruiting future students and potential participants from other divisions, and other organizational tasks as required for the project.

\section{Client Involvement and Instruction}

Clients were adults with intellectual disabilities who came to the community partner's habilitation center daily for assistance with personal and support services to achieve a wide range of personal goals. The clients who participated in the project were chosen by the community partner and included seven males, ranging in age from twenty-one to fifty-four years, and three females, one aged nineteen years and the other two aged thirty-six and thirty-seven years. Instruction took place at the community partner's site in a computer laboratory for which some of the equipment was purchased by the project. The clients received weekly technology instruction based on diagnostic tests at the beginning of the instructional period that established their baseline competencies and their personal goals for technology use. The original project contained six standardized modules with dynamic tracks for which instruction could be adjusted based on the individual client's needs. There are also interactive online tutorials, and the program has been expanded with additional modules as clients have mastered proficiency of the original six. Table 1 outlines the original Internet Training Modules and the recent addition of four Gmail Modules and two Computer Training Modules, designed and implemented by MLIS students which can be dynamically arranged to assemble or produce particular tracks based on client diagnostics and goals. This paper addresses the assessment of only the original modules since the newer modules have been developed only recently and there is no data to report as yet.

\section{Community Partner Involvement}

The community partner is a licensed nonprofit which offers a variety of programs including, but not limited to, adult companionship, residential habilitation, respite care, and sponsored employment. The partner collaborated closely with the university to develop the original grant proposal and provided guidance with project organization and implementation. Since the graduate students involved in the design and implementation of the training materials did not have formal instructional design background, nor, for that matter, practical experience in instructing people with intellectual disabilities, they worked closely with the community partner's experienced personnel to maximize the quality of the training program. Administrative matters and other project tasks were coordinated primarily between those MLIS students actively participating on the project and partner's Program Coordinator. Collaborations with other community partner administrators, e.g. the Program Manager for proposal development, the Day Habilitation Coordinator for assistance with training assessment, etc., were also instrumental for this particular project. The community partner provided the facilities, clients, and client assessment protocols, as well as guidance in working with the clients' personal instructional needs, all of which were invaluable to the success of the project.

\section{METHODS}

The method and results reported follow a qualitative reporting framework, utilizing emergent data analysis that approximates the method of conceptual framework delineated by Jabareen which names concepts, describes them, and categorizes them according to ontological, epistemological, and methodological functions. We also utilize White and Marsh's notion of inference to move from the cohesion and

\section{Table 1. Instructional Modules}

\section{Original Internet Training Modules}

Using Basic Features of Internet Explorer and Web Links

Searching For and Playing Videos on You Tube

Adding a Website to Your Favorites

Refining Your Google Search by Adding Search Terms

Refining Your Google Search by Using Quotations

Searching for Images on Google

\section{Gmail Modules}

Signing up for a Gmail Account

Writing and Sending an E-mail

Checking E-mail

Adding an E-mail Address to Contacts

\section{Computer Training Modules}

Personalize Your Desktop Background

and Screen Saver

Creating and Saving a Microsoft Word Document 
Table 2. Student Responses to Core Mapping Document (Summary)

\begin{tabular}{|c|c|c|c|}
\hline \multicolumn{2}{|c|}{ As Listed Below } & \multicolumn{2}{|r|}{ Please Provide Input } \\
\hline $\begin{array}{l}\text { Primary Tasks and } \\
\text { Responsibilities of } \\
\text { CTPD }\end{array}$ & $\begin{array}{l}\text { Core areas of LIS } \\
\text { education at SLIS- } \\
\text { UA }\end{array}$ & $\begin{array}{l}\text { MLIS courses that helped } \\
\text { with work at CTPD }\end{array}$ & $\begin{array}{l}\text { Exercises, tests, assignments, etc. from MLIS courses that } \\
\text { helped with work at CTPD }\end{array}$ \\
\hline $\begin{array}{l}\text { Experimental } \\
\text { (Research) }\end{array}$ & Methods & $\begin{array}{l}502(11) ; 507(2) ; 503 \\
560\end{array}$ & $\begin{array}{l}\text { "All of the coursework in LS- } 502 \text { Research Methods helped } \\
\text { my work on the CTPD project. The class consisted of as- } \\
\text { signments that were designed to approximate the writing } \\
\text { of a research proposal." } \\
\text { " } 507 \text { was an intensive course on how to find and evaluate } \\
\text { sources and information." }\end{array}$ \\
\hline $\begin{array}{l}\text { Project dissemina- } \\
\text { tion (Research) }\end{array}$ & LIS Socialization & $\begin{array}{l}502(3) ; 507(3) ; 560(4) \\
501(3) ; 500 ; 522 ; 590\end{array}$ & $\begin{array}{l}\text { "Again, it was very helpful to understand the basics of } \\
\text { how research should be set up and designed and this was } \\
\text { primarily seen through } 502 \text { and the research and papers } \\
\text { written in the class." } \\
\text { "Building a website, making Camtasia modules, studying } \\
\text { Web usability" }\end{array}$ \\
\hline $\begin{array}{l}\text { Modules (Instruc- } \\
\text { tion) }\end{array}$ & $\begin{array}{l}\text { Info tools and } \\
\text { services }\end{array}$ & $\begin{array}{l}560(11) ; 501(2) ; 505 \\
531 ; 500(4) ; 502 ; 504\end{array}$ & $\begin{array}{l}\text { "Adobe Captivate assignment" } \\
\text { "Tutorial creation" } \\
\text { "In this class we learned about the ASSURE model, which } \\
\text { gives in depth attention to designing a lesson plan." }\end{array}$ \\
\hline IT (Instruction) & Technology & $560(12) ; 504 ; 501 ; 590$ & $\begin{array}{l}\text { "I think the biggest help was working with various projects } \\
\text { in } 560 \text { " } \\
\text { "The usability assignment also required us to become } \\
\text { familiar with the IRB process." }\end{array}$ \\
\hline $\begin{array}{l}\text { Project manage- } \\
\text { ment (All) }\end{array}$ & Management & $\begin{array}{l}560(5) ; 522 ; 531 ; 533 \\
(4) ; 500 ; 501 ; 590(3)- \\
\text { Project Management; } \\
\text { 503-Systems Analysis; } \\
508(2)\end{array}$ & $\begin{array}{l}\text { "Budget project, scheduling" } \\
\text { "Learned various management techniques." }\end{array}$ \\
\hline
\end{tabular}

intentionality of the students' text to answering the research objectives posed by the study. ${ }^{14}$ This approach emphasizes the interdisciplinary influences of theory and practice on concepts associated with textual data analysis, and recognizes the flexibility required for qualitative reporting of the data. Due to the lack of sample size and comparative data, we employed simple descriptive statistics in analyzing quantitative data, where applicable.

\section{Student Data}

At the conclusion of their participation in the project, students were required to prepare a core mapping matrix, in which they were asked to associate and comment on which courses had contributed to five areas of responsibility with the project to assess the impact of a particular course or set of courses on each of the tasks and responsibilities associated with the CTPD service learning project. The core mapping exercise provided data concerning the relationship between the primary tasks and responsibilities of the CTPD and the core MLIS courses that enabled competence in each of five categories, two of which were research based (experimental and project dissemination), two of which were instructional (modules and instructional technology), and one which incorporated all phases of course work (project management). This assignment facilitated tracking of the core courses which most influenced the students' ability to perform tasks effectively (refer to table 2). Students were also required to write a reflective piece which communicated their overall impressions of the experience in narrative form. Reflection is recognized as a useful assessment measure for students in areas of personal growth and professional development. ${ }^{15}$ There were no parameters placed on the reflections, so the depth of writing varied from one paragraph to several pages. Both exercises were designed to elicit feedback about the program itself and the impact on the students as professionals entering the field of Library Science.

A total of thirteen student reflections were coded using an open coding descriptive method from which emerged four major categories: Personal, Project, Clients, and Project Team. The personal category included comments that described the student's internalized reactions and individual observations 
concerning the effect of their participation on them. The project category was comprised of comments concerning the project itself, including observations about various tasks and activities and working with the community partner. Client observations included comments pertaining to working directly with the clients, and project team commentary included reflections which concerned the faculty project investigator, project management, and aspects of working with the other project team members. From each category, concepts emerged which indicated the ways in which students internalized the experience, formed additional knowledge, and projected their realities onto their future professional landscape. The commentaries provided useful feedback on aspects of the project that need to be adjusted or expanded.

In addition to the reflective writing and core mapping exercises, students were asked to track each client's progress through testing and observational notes posted on a collaborative workspace in Google Docs. Testing data was entered on a spreadsheet to aggregate client progress records for data collection and analysis (refer to table 3). This enabled students new to the project to examine records for each client to assess the level at which interaction could take place going forward. This practice mitigated the need to perform assessment of client skill sets each time a new student joined the technology instruction team, providing greater continuity of instruction for the clients in the face of student turnover due to graduation from the program or attrition from the project.

\section{Client Data}

The instructional modules were designed for delivery through 15-minute, face-to-face sessions, up to twice each week, in which the students guided each client through a series of standardized steps to train in a particular competency. The clients were given a diagnostic test at the beginning of the instructional period that established their baseline competencies in web browser utilization. The same diagnostic test was given at the conclusion of the instructional period (approximately ten weeks later) to determine whether the competencies of the clients had improved. Each client was taken through the steps of a module for three consecutive instructional sessions and then given an examination in which they were asked to complete the tasks of the module without instructional assistance. If a client was able to complete all of the tasks in the module without error, they were then allowed to progress to the next module. If the client failed to complete the tasks, they received as many sessions of instruction as they needed to master the module and were tested again as soon as they felt they were ready. Students would continue to work with the clients on each module until proficiency was reached.

The project coordinators also maintain a Google Docs account to which students post information concerning the clients' progress in advancing through the instructional modules. Students devised a system of codes to identify clients to protect anonymity. Each client record contains demographic data, results of a diagnostic test to ascertain their level of technology literacy, notes on the instructional session, and updates each time a client is tested for learning on a particular module. Students developed a check list for the diagnostic tests and each of the modules to indicate the level of proficiency, or lack thereof, for each element denoted by a plus $(+)$ or minus (-) sign to aid in data collection and analysis. A spreadsheet is maintained that indicates each client's score for each module. Note that not all clients are tested at the same time, but are tested on a module only when they feel they are ready to advance to the next module. Also, all clients are not working on the same module simultaneously, but can work and advance at their own pace.

\section{Community Partner Data}

The center and program directors for the community partner were interviewed to ascertain the successes and challenges of the project from the community partner's point of view. Inclusion of community partners in the development, administration, assessment, and improvement of service learning projects provides greater insight into the actual needs of partners and clients, rather than those perceived by university researchers from a distance. ${ }^{16}$ The 45 -minute taped interview took place at the community partner's site in the computer lab to facilitate discussion of all aspects of the program. The director and program manager were asked (1) their general impression of the program, (2) the perceived benefits to their organization, (3) the perceived benefits to the center's clients, (4) issues and/or challenges for the program, and (5) what they would like to see going forward. After the interview was transcribed, a member check was performed to ensure that the directors' statements had been recorded accurately. Responses were coded using the same method as the student reflective papers.

\section{RESULTS}

Taken as a whole, these assessments provide a narrative that enables determination of the level of success in achieving the ostensible goals of the program, as well as providing a road map for necessary improvements and modifications to the course and program delivery. We were able to assess the two explicit goals of the program, MLIS curricular efficacy for the project and provision of technology instruction to intellectually disabled clients through triangulation between the core mapping worksheets, student reflections, and client progress reports. The interview data served as corroborating evidence to support the results of the other data collection tools and provided an additional perspective from the community partner's point of view. Overall, the results indicate that the project design and framework provide a practical blueprint for an instruction based technology literacy project that combines curriculum and service learning in a community partnership arrangement. The assessment instruments provided a variety of perspectives from which to gauge the efficacy of the MLIS 


\section{FEATURE}

Table 3. Progression through 6 Modules

\begin{tabular}{|c|c|c|c|c|c|c|c|c|c|}
\hline \multirow[b]{2}{*}{ Module } & \multicolumn{9}{|c|}{ \% Score (date) by Client Number } \\
\hline & 1 & 2 & 3 & 4 & 5 & 6 & 7 & 8 & 9 \\
\hline \multirow[t]{2}{*}{1} & $90(10 / 9 / 09)$ & $100(7 / 6 / 10)$ & $40(10 / 8 / 09)$ & $20(10 / 8 / 09)$ & $100(7 / 13 / 10)$ & $100(10 / 9 / 09)$ & $100(10 / 8 / 09)$ & $100(10 / 8 / 09)$ & $100(10 / 8 / 09)$ \\
\hline & $100(10 / 21 / 09)$ & & $100(10 / 28 / 09)$ & 100 (n.d.) & & & & & \\
\hline \multirow[t]{2}{*}{2} & $30(10 / 22 / 09)$ & $\begin{array}{c}100 \\
(7 / 20 / 10)\end{array}$ & $100(11 / 12 / 09)$ & $100(11 / 18 / 09)$ & $100(7 / 20 / 10)$ & $100(10 / 22 / 09)$ & $100(11 / 12 / 09)$ & 80 (no date) & $100(10 / 22 / 09)$ \\
\hline & $100(11 / 11 / 09)$ & & & & & & & $100(11 / 12 / 09)$ & \\
\hline \multirow[t]{3}{*}{3} & $30(4 / 26 / 10)$ & $100(9 / 17 / 10)$ & $100(4 / 28 / 10)$ & $90(4 / 28 / 10)$ & $100(7 / 27 / 10)$ & $100(11 / 12 / 09)$ & $100(4 / 28 / 10)$ & $100(4 / 28 / 10)$ & $100(11 / 12 / 09)$ \\
\hline & & & & $60(7 / 1 / 10)$ & & & & & \\
\hline & & & & $100(10 / 5 / 10)$ & & & & & \\
\hline 4 & & $100(10 / 15 / 10)$ & $100(7 / 20 / 10)$ & & $100(9 / 21 / 10)$ & & $100(10 / 22 / 10)$ & $100(7 / 1 / 10)$ & $100(4 / 28 / 10)$ \\
\hline 5 & & & $100(9 / 21 / 10)$ & & $100(9 / 28 / 10)$ & & & $100(7 / 29 / 10)$ & \\
\hline 6 & & & & & $100(10 / 5 / 10)$ & & & $100(9 / 21 / 10)$ & \\
\hline
\end{tabular}

courses in preparing students for participation in the project, but also identified the need to reassess how service learning is incorporated into the curriculum. In addition, the absence of a baseline for assessing the effects of technology instruction for the clients provides evidence for the need to establish benchmarks for successful client instruction. The project, as a whole, supports reflective practice as an important pedagogical practice. ${ }^{17}$

\section{Core Mapping Worksheet}

A list and summarized description (taken from the university course catalog) of the core courses include:

- LS 500-Organization of Information: Introduce principles of organizing library catalogs and collections; course objective is to enable the student to understand the basic structure(s) of various search tools.

- LS 501-Introduction to Library and Information Studies: Provide students with a broad background in library and information studies, socialization to LIS.

- LS 502-Research Methods: Introduce research design and statistical techniques; students should be able to design and carry out basic research projects.

- LS 507-Information Sources and Services: Introduce printed and digital reference sources and reference services.

- LS 508-Administration and Management: Introduce theory and practice by studying communication, decisionmaking, delegation, personnel, budgeting, etc.

- LS 560_-Information Technology: Planning for and implementing an automated library system; the library of the future (under revision).

- LS 504-Media Production and Utilization (school media certification only): Training modules for basic skills in preparing and utilizing educational media.

While it was clear that each course in the curriculum contributed in some way to the students' competence in carrying out their tasks, two courses were perceived to contribute more fully. Research Methods was cited by eleven out of thirteen students as the primary course that facilitated data collection and analysis, and writing problem statements, literature reviews, and proposals. The main goal of the course is to enable students to design and carry out basic research projects. Information Technology was cited by eleven of thirteen and twelve of thirteen respectively, as the primary course in the categories of module development and technology instruction (one student had not yet taken this course). Students learned to create tutorials, specifically using Captivate software, and to develop lesson plans utilizing the ASSURE model for instructional design. (ASSURE is an acronym for Analyze learners; State objectives; Select methods, media, and materials; Utilize media and materials; Require learner participation; Evaluate and revise). Table 2 displays a summary of student responses to the core mapping worksheet. Column 3 indicates the course(s) the students cited as most helpful to the primary tasks and responsibilities listed in column 1 , and column 4 contains sample quotes from the students concerning the course components that enabled them to fulfill the corresponding tasks and responsibilities. The number in parentheses following the course designation in column 2 indicates the number of students who cited the course as helpful to the task.

We reported previously on the specific applications and analyses of the core curriculum. ${ }^{18}$ However, we believe that ongoing assessment and revision will supply information necessary to refine and update the MLIS curriculum as the program expands.

\section{Personal Reflections}

In the area of personal feelings about the project, themes of reward, insight, confidence, and gratefulness repeated frequently. Students viewed their involvement in the project as personally rewarding, but many did not articulate how those rewards were manifested. Students employed generalized perceptions, such as "there is no better feeling in the world than to help someone," voicing their desire to "be involved in something bigger than yourself" and "do something simple and useful for members of your community." They described their involvement with adjectives, such as "illuminating," 
"joyful and insightful," "eye opening," "challenging," "rewarding," and "amazing." They also indicated that they had gained insight into a population with whom they had heretofore little or no experience, as well as into their own assumptions and biases concerning intellectually disabled populations, a goal that is supported in the literature. ${ }^{19}$ Some students expressed initial feelings of apprehension or intimidation concerning their ability to teach effectively, but in each case, students ultimately cited increased personal confidence in their ability to provide instruction to disparate populations, gaining new skill sets, and conveying gratefulness for the opportunity to participate in the project. Statements such as, "I learned not to judge people on the outside" and "I very quickly realized that the vast majority of my concerns were not going to be problems" indicate the desired positive outcomes for students who may have entertained stereotypes or negative attitudes toward those with intellectual disabilities.

The implication is that the concept of empowering disadvantaged groups is a rewarding experience, and the students gained knowledge that altered their existing realities to include the need to recognize and assist underrepresented populations. However, that was expressed more clearly in their discussions of the clients, rather than themselves. Since one of the goals of the project is to channel students into careers as library professionals committed to community engagement, the foundational knowledge gained in the core competencies was applied to experiential learning in the field which centered on successful interactions with clients, as well as personal and professional benefits, a hallmark of Glazier and Grover's Circuits of Theory approach applied to the project framework. ${ }^{20}$

The project category commentaries were divided between the instructional activities, the larger significance of the project to the students' future as library professionals, and the community partner's importance to achieving success in the instructional and interpersonal goals of students and clients involved. Students discussed multiple aspects of teaching technology, particularly the specialized nature of teaching the intellectually disabled. One student captured the essence of the experience, observing "Students are exposed to the information needs (and other needs, such as emotional needs) of clients" and "Future librarians will experience many of these same types of clients." The teaching and technology aspects of the experience related directly to the core competencies in the MLIS program, providing a measure of validation for the importance of the core in equipping the students for the tasks associated with the project.

Students repeatedly praised the director and staff of the community partner as crucial and committed participants in improving the quality of life for the clients. However, one of the critical deficiencies of the project is the lack of technology skills for most of the staff. The staff members, while committed to other areas of life enhancement for the clients, were unable to assist the clients with technology activities in the absence of the MLIS students. This observation was later corroborated in the interview with the community program director. One student also indicated that there should be greater coordination between students and the staff, saying "One other step that would greatly increase the success of the instructional modules with each specific client would be to discuss their individual deficiencies with the individual(s) on the RFI staff in charge of their Individualized Plan and make sure these deficiencies are being addressed." In addition, the students participate only until they graduate, so the rate of turnover presents logistical and relationship challenges to continuity for the clients. Moreover, the students recognized the importance of such a service to the community and expressed the desire for the project to continue and expand after their tenure. The concept of service was reinforced by the students' interactions with the staff and clients.

Observations regarding the clients were uniformly positive, mostly revealing the pleasure and reward derived from teaching and interacting with them. While there was recognition that many of the clients would never be employable or able to live completely independently, there was also general agreement that the technology skills they gained were an important factor in building their independence and selfefficacy. Clients were also recognized as individuals, each with his/her own personality, interests, and stories. Students were able to dispel stereotypes assigned to intellectually disabled populations, and realize that underrepresented groups require and deserve advocacy. Student comments included "people with disabilities are exactly like everyone else," "they deserve to live full, meaningful lives," "they deserve skills to help them assimilate and better function in society," and "people with disabilities are often extremely marginalized." Some students expressed an emotional attachment to the clients they served, indicating that hugs and high-fives were an important part of their relationships. A change in worldview from self to other was the eventual outcome of the interactions provided by the teaching experience, reinforcing the concept of service.

Students also viewed the team experience as a valuable skill builder that would serve them as professionals. They gained valuable knowledge in planning, coordinating, and delivering instruction, as well as strengthening organizational and pedagogical skills. Students made comments such as participation in the project "strengthened my organizational and pedagogical skills" and that they "learned to work effectively as part of a team." These were components of the core competencies relevant to project tasks and responsibilities and pertinent to overall project goals. It is necessary that students become skilled team players as the professional world largely requires collaboration and cooperation between professionals individually and at the organizational level. ${ }^{21}$ Students also discussed the increase in their own technology skills by learning to use Captivate to create instructional modules and Google Docs to share knowledge and insights with other team members. The concept of collaboration emerged as a material element in the overall success of the project. This was especially true for the two project managers who had responsibility for such critical activities as coordinating team activities and meetings, locating funding sources, and writing grant proposals. Courses in 


\section{FEATURE}

administration and management were instrumental in the project managers' capacity as organizers and leaders, mimicking professional roles and responsibilities.

\section{Client Progress}

Ten clients have been served by the student instructors at the $1^{1 / 2}$ year mark. Table 3 displays the clients' progression through the instructional modules in the first eighteen months of the program. Clients are listed numerically to protect anonymity.

Two clients have reached proficiency on six original instruction modules, and surprisingly, one client is speech and hearing impaired, and must communicate through sign language. However, the client has been able to teach the students some signing to enable two-way communication. The other client mastered the modules in less than three months. So, of the ten clients served by the program thus far, over half have reached a proficiency level that enables them to browse and search the web and interact with You Tube videos, including the two clients who are no longer in the program. Client 9 left the program voluntarily (the reason was not recorded), but has returned since the start of the new Gmail and Computer Training Modules, and Client 6 is no longer a client of the community partner. Client 1 has been unable to progress beyond Module 3. Client 10 has been with the program for only two months and has not yet mastered Module 1. The gap in progress between November 2009 and April 2010 is partially the result of the semester ending and student turnover in the new semester. In addition, there was no Internet conductivity on two of the visits in early 2010, so no instruction took place. The lack of recorded dates for two of the client scores reveals the need for rigorous and systematic control over the client data.

The students' notes acknowledge that, for most clients, long gaps in instruction necessitate remedial work to prepare them to progress to the next module. However, one of the students' concerns, the widely varying levels of cognitive ability and initial proficiency of the clients, is corroborated by the client progress data. The notes also indicate that most of the clients have worked enthusiastically to master the steps in each module, and the students indicate that both they and the clients are excited when they see real progress toward independent use of technology. The explicit benefit to the students is their responsibility for design and implementation of the research project and seeing it to fruition. The ostensible goals of student involvement in all phases of the project and instruction to clients were fulfilled, along with the additional value of student reflections which indicated the students' recognition that such service will become integral to their profession. Students also felt empathy for the clients who struggled to become independent, an important component in serving underrepresented populations.

\section{Community Partner Interview}

Feedback from the community partner's perspective was generally enthusiastic concerning the program and the presence of the students, and they expressed gratitude for the university's provision of computer equipment, instruction modules, and instructors. Partnership with the university provides the organization with greater visibility and increased access to potential volunteers since they could participate in awareness activities, such as the university's "Get on Board Day" which showcases myriad organizations and activities in which students can become involved, and presents additional opportunities to attract funding from the population at large. The staff benefits from the professionalism and expertise of the MLIS students, and the clients are empowered by their participation in a challenging activity that enables them to connect with the world outside of the center. The center director noted that the computer instruction provided by the students had redirected the clients' interest from watching television and playing video games to working on the computer.

Many of the issues and challenges raised by the directors mirrored those of the students in their reflective essays. Students are available only as long as they are enrolled in the program, and while a few of them may be available after they graduate, most of them relocate for purposes of employment. RFI staff are in need of technology education so that they are able to assist the clients with computer literacy in the absence of the MLIS students. Also, instructional modules need to be modified to accommodate clients who are more intellectually advanced to keep them from getting bored or frustrated, and there is a need for equipment and programs for clients who have physical rather than intellectual disabilities, such as hearing impairment and dexterity challenges. The directors also expressed the desire to see the program expand to include additional instructional opportunities, as well as on campus visits for the staff and clients and remote learning opportunities through Skype, Wimba, and other protocols. The ubiquitous need for funding for nonprofit organizations remains an issue, although they were appreciative of the funding that provided the initial equipment, software, and personnel.

\section{LIMITATIONS, DISCUSSION AND LESSONS LEARNED}

Results were reported using mainly qualitative methods of text analysis because of the small sample size of both students and clients. Simple descriptive statistics provided a quantitative illustration of core course efficacy and client progress. Since this paper assessed the first eighteen months of the project from its inception, the data provide only a baseline from which to measure ongoing progress as the project advances and expands. We were unable to establish benchmarks for benefits to students, clients, and the community partner, but triangulated the data to assess the achievement of the two explicit and three implicit project goals. We expect ongoing data collection to yield additional insights that will enable a mixed methods approach to assessment to allow us to perform both qualitative and quantitative evaluation of data. 
The results of the core mapping worksheets reveal that the MLIS core courses did contribute to the students' competence in several ways, including research, planning, managerial, and technology skills, but two courses, Research Methods and Information Technology were viewed by the students to be the most effective courses in preparation for participation in this project. The initial phase of the project required a great deal of planning and research, and the project coordinators indicated that Administration and Management provided them with a solid background in the necessary managerial skills to implement and execute the project. While the core courses are helpful in preparing students to participate in the project, there yet exists no course which specifically addresses service learning and community partnership as a scholarly endeavor. While projects such as this encourage students to engage in the research aspects of service learning, the scholarly pursuit of community engagement, its deeper meanings and applications, and eventual commitment to civic responsibility in the professional sphere are addressed only peripherally. ${ }^{22}$ There is evidence that service learning courses can be woven successfully into the core curriculum and certification programs. ${ }^{23}$ One study reveals that a required service-learning curriculum provides a valuable "structured experience that combines service in a community setting with reflective learning." 24 The benefits of inclusion of such courses to the students and communities in the form of increased commitment to engage responsibly are well documented. ${ }^{25}$

The practice of reflection provides students with a form of learning that enables them to synthesize their affective processes in adopting a community engagement posture and changing attitudes toward community partners. ${ }^{26}$ The students' reflections reveal that for those who were apprehensive about participating in the project, whether it concerned their teaching ability, fear of technology, or discomfort in involvement with cognitively challenged clients, the experience provided a useful platform for overcoming those fears. In addition, students tended to be grateful for the experience and expressed a heightened interest in continuing service work as professionals. They genuinely enjoyed their time with the clients and uniformly praised the community partner for their commitment to the clients. For many of these students, the goal of expanding their worldview to include underrepresented or marginal groups provides a foundation for lifelong community engagement practices, a cornerstone of service learning initiatives and highly applicable to public library professionals. The drawback of some students having only one semester in the project before graduation from the MLIS program can be overcome by having mechanisms in place to provide for a smooth transfer of information to the new group of student instructors, an objective accomplished through the Client Progress Reports.

One of the unintended effects of the project was that of the students learning from the clients, especially noted for the client who is speech and hearing impaired. The students' initiative in learning to sign to communicate with the client signaled an adaptive scenario to fill the needs of the client. In addition, this client was intellectually adept, easily finishing all six modules, but lacked the capabilities to communicate effectively with the instructors, necessitating the use of sign language. This illustrates the value of collaboration with the community partner with the ideal that learning should be a symbiotic relationship between the university and its partners. ${ }^{27}$ This circumstance also revealed a need for additional software and modules for those with physical challenges who may be more intellectually able. There is no measure of actual program success for the community partner other than the progress made by the clients, and there is no way to know whether the technology literacy gained by the clients represents adequate progress toward independent use of technology. The progress of clients served by the initial phase of the project can be used as a benchmark for future clients as the program progresses and expands.

The community director and program manager's remarks serve to reinforce the students' reflections and observations. The community partner views the collaboration and association with the university favorably, expressing a desire for the university's role to expand to grow the program. There is a need to secure additional resources to expand the program to offer technology training to staff members who are technologically challenged and to secure additional hardware and software for other purposes. This is a circumstance which affirms the need to communicate and work closely with community partners to include them in plans to secure additional funding. Project planners must anticipate the future needs of the clients who complete the initial instruction modules and have no other avenues for technology instruction. The community director points to the need to provide life skills modules for the clients, an integral part of the realization of the clients' dreams of independent living. Service programs must not be viewed merely as a means to an end for educators and students, but as true partnerships in which the community members take an active role in planning, implementation, and expansion. ${ }^{28}$

While there is disagreement concerning the generalizability of qualitative research efforts since "phenomena are neither time- nor context-free"29 and human behavior is "heavily mediated by the context in which it occurs," ${ }^{30}$ the concepts of comparability and transferability apply more accurately. Comparability refers to how detailed components of the study are such that they provide a good basis for comparison to other studies, and transferability refers to the clarity of the theoretical underpinnings and research techniques of the project such that they can be directly applied to another study. ${ }^{31}$ One longitudinal study, conducted over a 20-year period, revealed four major propositions concerning service learning that suggest further research: (1) service-learning courses should be required and for credit, (2) students need a variety of flexible service-learning opportunities, (3) student growth results from increased leadership and involvement, and (4) rewarding excellence supports a robust ongoing service effort. ${ }^{32}$ One of the implicit goals of the CTPD project's design and techniques for an instruction-based 


\section{FEATURE}

service learning program is the extent to which they can be implemented in other programs. Circuits of Theory, which supplies the theoretical foundation of the program, grounds observation of phenomena with personal experience, providing a practical application for service learning curriculum that privileges authenticity and participatory pedagogies. ${ }^{33}$ Curricular modifications, coupled with reality-based practice, provide students with a grounded approach to professional community engagement.

\section{FUTURE RESEARCH}

There is much to be gained from this assessment that will inform future research, not the least of which is the pedagogical and theoretical frameworks which guided the initial phase of the project. Utilizing the core courses of the MLIS program as the pedagogical vehicle through which students gain the necessary project design and implementation skills presents valuable insights into course evaluation and design at the curricular level. There is also the need to explore inclusion of service learning and community engagement courses as integral to LIS curriculum. This necessitates a discussion of a standardized delivery format such that the content in these courses can be revised for use in the wider university community. Community engagement will continue to be a driving force behind universities who seek to remain relevant to the communities in which they are located and for students who view the university as a venue from which a community service worldview should emanate.

This project will eventually facilitate (1) the formation of new partnerships in the community surrounding the sponsoring University, (2) additional information literacy services for a variety of diverse populations, (3) cooperative relationships among LIS programs in the southeastern region of the United States, and (4) the preparation of future professional librarians for careers in community service. As the program is refined and expanded, additional knowledge will contribute to partnerships in ways that will facilitate providing technology literacy services to underrepresented populations to empower them as members of the community.

\section{References}

1. Dan Albertson and Maryann S. Whitaker, "A Service-Learning Framework to Support an MLIS Core Curriculum," Journal for Education in Library Science 52, no. 2 (2011): 152-63; Dan Albertson, Maryann S. Whitaker, and R. Alexander Perry, "Developing And Organizing a Community Engagement Project That Provides Technology Literacy Training to Persons With Intellectual Disabilities," Journal for Education in Library Science 52, no. 2 (2011): $142-51$

2. Alexander W. Astin et al., "Executive Summary: How ServiceLearning Affects Students," Higher Education Research Institute, University of California, Los Angeles, Jan. 2004, www.gseis.ucla .edu/heri/PDFs/rhowas.pdf (accessed Feb. 11, 2011); April K. Heiselt and Robert E. Wolverton, "Libraries: Partners in Linking College Students and their Communities through Service Learning," Reference \& User Services Quarterly 49, no. 1 (Fall 2009):
83-90.

3. Stephanie Sterling Brasley, "Effective Librarian and Discipline Faculty Collaboration Models for Integrating Information Literacy into the Fabric of an Academic Institution," New Directions for Teaching E Learning no. 114 (Summer 2008): 71-88.

4. Frances Jacobson Harris, Lori Arp, and Beth S. Woodard, "Information Literacy in School Libraries," Reference \& User Services Quarterly 42, no. 3 (Spring 2003): 215; John S. Riddle, "Where's the Library in Service Learning? Models for Engaged Library Instruction," Journal of Academic Librarianship 29, no. 2 (Mar. 2003): 71.

5. Carolyn Bourke, "Public Libraries: Partnerships, Funding and Relevance," APLIS 20, no. 3 (Sept. 2007): 135-39.

6. Patricia Montiel-Overall, "Teacher and Teacher-Librarian Collaboration: Moving Toward Integration," Teacher Librarian 34, no. 2 (Dec. 2006): 28-33; Jeff Siegel, "Keeping Creoles and Dialects Out of the Classroom: Is It Justified?" in Dialects, Englishes, Creoles, and Education, ed. S.J. Nero (Mahwah, N.J.: Lawrence Erlbaum, 2006): 39-67.

7. Brasley, "Effective Librarian"; Sandra Cuban and Elisabeth Hayes, "Perspectives of Five Library and Information Studies Students Involved in Service Learning at a Community-Based Literacy Program," Journal of Education for Library \& Information Science 42, no. 2 (Spring 2001): 71-88; Heiselt and Wolverton, "Libraries: Partners in Linking"; Michelle Kaarst-Brown et al., "Organizational Cultures of Libraries as a Strategic Resource," Library Trends 53, no. 1 (Summer 2004): 33-53; Bharat Mehra, "Library and Information Science (LIS) and Community Development: The Use of Information and Communication Technology (ICT) Towards a Social Equity Agenda," Community Development: Journal of the Community Development Society 36, no. 1 (2005): 28-40; Edward K. Owusu-Ansah, "Information Literacy and Higher Education: Placing the Academic Library in the Center of a Comprehensive Solution," Journal of Academic Librarianship 30, no. 1 (Jan. 2004): 3-16; Lorna Peterson, "A Brief History of ServiceLearning in LIS," in Service-Learning: Linking Library Education and Practice, ed. Loriene Roy, Kelly Jensen, and Alex Hershey Meyers (Chicago: ALA, 2009): 1-4; Loriene Roy, Kelly Jensen, and Alex Hershey Meyers, eds., Service-Learning: Linking Library Education And Practice (Chicago: ALA, 2009); Elaine Yontz and Kathleen de la Peña McCook, "Service-Learning and LIS Education," Journal of Education for Library \& Information Science 44, no. 1 (Winter 2003): 58-68.

8. Cary Meltzer Frostick, "The Myth of Equal Access: Bridging the Gap with Diverse Patrons," Children \& Libraries 7, no. 3 (Winter 2009): 32-37.

9. Albertson and Whitaker, "Service-Learning Framework."

10. Ibid.

11. Phillip M. Edwards, "Theories-in-Use and Reflection-in-Action: Core Principles for LIS Education," Journal of Education for Library E Information Science 51, no. 1 (Winter 2010): 18-29.

12. Kerry Ann Rockquemore and Regan Harwell Schaffer, "Toward a Theory of Engagement: A Cognitive Mapping of Service-Learning Experiences," Michigan Journal of Community Service Learning (2000): 14-25

13. Cushla Kapitzke, "Information Literacy: A Review and Poststructural Critique," Australian Journal of Language \& Literacy 26, no. 1 (2003): 53-66.

14. Yosef Jabareen, "Building a Conceptual Framework: Philosophy, Definitions, and Procedure," International Journal of Qualitative Methods 8, no. 4 (Dec. 2009): 49-62; Marilyn Domas White and Emily E. Marsh, "Content Analysis: A Flexible Methodology," Library Trends 55, no. 1 (Summer 2006): 22-45.

15. Edwards, "Theories-in-Use"; Tricia McClam et al., "An Analysis of a Service-Learning Project: Students' Expectations, Concerns, and Reflections," Journal of Experiential Education 30, no. 3 (Mar. 2008): 236-49. 
16. Heiselt and Wolverton, "Libraries: Partners in Linking"; John L. McKnight, "Redefining Community," Social Policy 23, no. 2 (1992): 56-62; Riddle, "Where's the Library."

17. Margaret E. S. Forrest, "On Becoming a Critically Reflective Practitioner," Health Information \& Libraries Journal 25, no. 3 (Sept. 2008): 229-32; Carol A. Marchel, "Evaluating Reflection and Sociocultural Awareness in Service Learning Classes," Teaching of Psychology 31, no. 2 (Spring 2004): 120-23; Rockquemore and Schaffer, "Toward a Theory of Engagement."

18. Albertson, Whitaker, and Perry, "Developing and Organizing."

19. Rockquemore and Schaffer, "Toward a Theory of Engagement."

20. Albertson, Whitaker, and Perry, "Developing and Organizing."

21. Susanna Bihari Axelsson and Runo Axelsson, "From Territoriality to Altruism in Interprofessional Collaboration and Leadership," Journal of Interprofessional Care 23, no. 4 (July 2009): 320-30; Keith Curry Lance, Marcia J. Rodney, and Bill Schwarz, "Collaboration Works-When It Happens!" Teacher Librarian 37, no. 5 (June 2010): 30-36; Diane C. Reep, Technical Writing: Principles, Strategies, and Readings (New York: Pearson Education, 2009).

22. Laura A. Lowe and Jeff Clark, "Learning about Social Work Research through Service Learning," Journal of Community Engagement \& Scholarship 2, no. 4 (Summer 2009): 50-59.

23. Dian Dudderar and Lois T. Tover, "Putting Service Learning Experiences at the Heart of a Teacher Education Curriculum," Educational Research Quarterly 27, no. 2 (Dec. 2003): 18-32.

24. Douglas M. Post et al., "Twenty Years of Experience in ServiceLearning at The Ohio State University College of Medicine," Journal of Community Engagement \& Scholarship 2, no. 1 (2009): 18-30.

25. Nathan J. Averill et al., "A First-Year Community-Based Service Learning Elective: Design, Implementation, and Reflection," Teaching \& Learning in Medicine 19, no. 1 (Winter 2007): 47-54; Kathy R. Fox, "Children Making a Difference: Developing Awareness of Poverty Through Service Learning," Social Studies 101, no. 1 (Dec. 2009): 1-9; Heiselt and Wolverton, "Libraries: Partners in
Linking"; Nancy K. Herther, "Service Learning and Engagement in the Academic Library," College \& Research Libraries News 69, no. 7 (July 2008): 386-89; Riddle, "Where's the Library"; Clara L. Sitter, "Learning by Serving," Knowledge Quest 34, no. 5 (May 2006): 23-26.

26. Sarah L. Ash and Patti H. Clayton, "The Articulated Learning: An Approach to Guided Reflection and Assessment," Innovative Higher Education 29, no. 2 (Winter 2004): 137-54; Morris Fiddler and Catherine Marienau, "Developing Habits of Reflection for Meaningful Learning," New Directions for Adult \& Continuing Education no. 118 (Summer 2008): 75-85; Forrest, "On Becoming a Critically Reflective Practitioner"; Marchel, "Evaluating Reflection"; Rockquemore and Schaffer, "Toward a Theory of Engagement."

27. McKnight, "Redefining Community."

28. Heiselt and Wolverton, "Libraries: Partners in Linking"; Herther, "Service Learning and Engagement"; McKnight, "Redefining Community"; Mehra, "Library and Information Science"; Riddle, "Where's the Library"; Roy, Jensen, and Meyers, "Service-Learning: Linking."

29. Egon G. Guba and Yvonna S. Lincoln, "Epistemological and Methodological Bases of Naturalistic Inquiry," Educational Communication \& Technology: A Journal of Theory, Research \& Development 30, no. 4 (1982): 233-52.

30. Egon G. Guba and Yvonne S. Lincoln, Effective Evaluation: Improving the Usefulness of Evaluation Results Through Responsive and Naturalistic Approaches (San Francisco: Jossey-Bass, 1981).

31. Judith P. Goetz and Margaret Diane LeCompte, Ethnography and Qualitative Design in Education Research (Orlando, Fla.: Academic Pr., 1984)

32. Post et al., "Twenty Years of Experience."

33. Albertson, Whitaker, and Perry, "Developing and Organizing"; Jack D. Glazier and Robert Grover, "A Multidisciplinary Framework for Theory Building," Library Trends 50, no. 3 (Winter 2002): 317-29. 